\title{
Keeping the human: neuroethics and the conciliation of dissonant values in the 2 Ist century
}

This article was published in the following Dove Press journal:

Neuroscience and Neuroeconomics

13 April 2015

Number of times this article has been viewed

\section{Adriana Gini ${ }^{1,2, *}$ \\ Denis Larrivee $2,3, *$ \\ Michele Farisco ${ }^{4,5}$ \\ Vittorio Alessandro Sironi ${ }^{6}$}

'Neuroradiology Division,

Neuroscience Department,

San Camillo-Forlanini Medical

Center, Rome, Italy; ${ }^{2}$ International

Neuroethics Society, Bethesda, MD,

USA; ${ }^{3}$ Educational Outreach Office,

Catholic Dioceses of Charleston, SC,

USA; ${ }^{4}$ Centre for Research Ethics and

Bioethics, Uppsala University, Uppsala,

Sweden; ${ }^{5}$ Biogem Genetic Research

Center, Ariano Irpino, Italy; ${ }^{6}$ Research

Center on the History of Biomedical

Thought, School of Medicine and

Surgery, University of Milano-Bicocca, Milan, Italy

*These authors contributed equally to this work
Correspondence: Adriana Gini

Neuroradiology Division, Neuroscience

Department, San Camillo-Forlanini

Medical Center, via Circonvallazione

Gianicolense, 87, Rome 00152, Italy

Tel +3906 58704378

Fax +3906 5870 449I

Email adrianagini@yahoo.it
Abstract: Studied since antiquity, the human brain has recently been the inspiration for an international neuroscientific entrepreneurship, the Human Brain Project in Europe and the Brain Research through Advancing Innovative Neurotechnologies initiative in the USA. Different in their approach, both regard the human brain as one of the greatest challenges of 21 st century science and the organ that makes us "human". However, it is mainly the necessity of developing new therapies that affect up to a billion people worldwide, which has propelled the search for extensive expertise and investment in neuroscience research. The debate on ethical and social policy issues as well as the research and medical strategies of such gigantic efforts has involved participants as diverse as neuroscientists, philosophers, scholars in ethics and law, politicians, and the general public, rendering modern neuroscience an interdisciplinary and conflictual endeavor. In fact, the brain is described as the biological underpinning of our thoughts, emotions, perceptions, free willed actions, and memories, features unique to our humanity. In this review, three neuroscientists and a philosopher from the neuroethics community provide their perspectives for an up-to-date survey of salient neuroethical issues, ie, modulation of free will and neuropharmaceuticals and neurotechnologies that enhance cognitive capacities, as well as an introduction of the reader to the controversial new discipline of neuroethics. Written for nonexperts in the field, it is intended to reflect on and to impart information helpful in understanding the challenges and the perils of modern neuroscience, whose tools are so powerful as to jeopardize what is uniquely "human" through willful mind manipulation. We conclude that, for any future effort to "recreate" the mind and, at the same time, keep what is uniquely ours, it will be necessary to reflect ethically and review carefully man's past best efforts at self-understanding.

Keywords: neuroethics, free will, neuromodulation, human nature, neuroscience, neurophilosophy

\section{Introduction}

It is truly an exciting time in neuroscience. A major and foundational era is ending. A new, more integrative phase is about to begin. For 100 years neuroscience has labored to understand the constituency of the brain, its functional units, their operations, and how they interact to build up the brain. Its philosophy "principale" was predicated on a parts-determines-whole-approach that informed a research directed to the manner in which the brain was built from the bottom up, an operational philosophy termed neuroreductionism. Instead, the new neuroscience considers the operations of hundreds of thousands of neurons working in unison and the manner in which their concerted operation constrains output, a philosophy of systems and downwardly operative effects. Connectomes, the term for large-scale circuit structures, are now variously explored in Caenorhabdites, Drosophila, Aplysia, zebrafish, nonhuman primates, and even humans. ${ }^{1}$ 
No longer preeminent, neuroreductionism is ceding to a science of complexity its revelatory promise of globally operative constructs, a neo-Aristotelian predilection once thought sterile and lacking in conceptual power. Increasingly evident are emergent features originating in dimensions such as relationality, language, and reflexive consciousness that condition lower level processes and are not explanatory by neuroreductive philosophy. These studies will help to illuminate the unity underlying our sense of self and our capacity to relate to neighbor and environment. They will also draw us closer to an understanding of the complexity intrinsic to the human brain, with an excess of 100 billion neurons at its disposal. Whether they can extract the mystery of the human mind, which most neuroscientists believe is ultimately reducible to the human brain, may yet remain a storied promise for future phases.

The human mind is variously responsible for all of man's cultural achievements, from art, to scholarship, to civilization. Its power rests on some of its most vaunted possessions, its capacity for rational inference and its connotative operations and for self-governed movement. Their use has permitted the enormous range of conceptual work that is man's patrimony. The service these have rendered culturally, though, reflect deeper aspects of the human mind, its orientation toward truth as an objective reality, its relational nature for service and participation, its grasp toward perfection and beauty, and its striving for an ascending participation in existence. These primal elements constitute the deep background against which the operational features of the mind are conditioned.

How the mind emerges from the brain remains a mystery, but the brain's material contribution to the mind's operation seems undisputed. Today's research seeks both to understand and to restore. More than 1,000 disorders of the brain and nervous system result in more hospitalizations than any other disease group, including heart disease and cancer. In 2007 , the World Health Organization estimated that neurological disorders affect up to one billion people worldwide. In fact, neurological diseases make up $11 \%$ of the world's disease burden, not including mental health and addiction disorders. ${ }^{2}$ The cost of these diseases is high across the globe. For example, the European Brain Council estimated that neurological diseases in Europe alone cost one trillion dollars per year in 2010. ${ }^{3,4}$ Much will be learned as huge projects in Europe and the USA, the Human Brain Project and the Brain Research through Advancing Innovative Neurotechnologies initiative, march forward.

But, with the greater understanding and solutions to therapeutic quandaries, there arise notions of whether and how the mind may be improved. Already technologies greatly amplify motoric capabilities which bypass their biological effectors. Centrally mediated behaviors such as the emotions or decision making, moreover, are now objects of proposed modulation. In such efforts the question of what is to be gained is pertinent. Cognitive abilities? Motor skills? Behavioral modification? Or are we seeking to transform even more singular elements that serve as the ground for its operations and that condition what these are directed toward? Should we? What do we prize in our human nature, and how can we keep it?

\section{A distinctive neuroanatomy}

Since Ramon de Cajal's confirmation of the neuron doctrine, the human brain's physical configuration has been characterized from numerous vantages now summarized in a spectrum of atlases depicting gross, connectivity, topographical, and other profiles. What seems distinctive in humans, with no close parallel among other primates, is the enormous mass of brain tissue devoted to association cortical circuitry. ${ }^{5}$ Whereas sensory and motor cortical areas appear to be proportionally scaled relative to association cortex among other primate species, in humans the ratio rises to more than three times that of any near neighbor, such as the chimpanzee. The size increase, moreover, is not simply due to an incremental mass in comparable circuitry, but one of novel and physiological significance. ${ }^{2}$ In other primate species, many cortical circuits are organized as serial hierarchical pathways in which sensory information is transformed through feed forward pathways to guide relatively immediate output reactions. The association cortex of humans, by contrast, emphasizes densely developed interconnections in association circuitry that is widely distributed among numerous cortical centers. Functional magnetic resonance imaging (fMRI) studies ${ }^{6}$ confirm the presence of multiple, large-scale distributed networks spanning all of the major centers of the association cortex including the prefrontal, temporal, parietal, and cingulate cortices. Connectivity to sensory and motor cortex areas, relatively speaking, is minimal. The resulting information flow through such circuits, thus, appears patterned after parallel and reentrant processing, suited to top down control and internal mentation.

An illustrative case of a neural center exhibiting such multiform connectivity and for which task complexity is obviously higher order and multimodal is the hippocampus. This center has been well characterized for its contribution to memory and has been variously implicated in spatial, declarative, recognition, episodic, explicit, learning, and long-term mechanisms of recollection. ${ }^{4,6-8}$ The plethora of empirical information relating 
to this structure has in turn generated numerous theories of function including, the Multiple Trace Theory, Dual Process Theory, and the Relational Theory, as well as attempts to acquire a neural level understanding relating function to their cognitive domain distribution, such as the Cognitive Map Theory. Anatomically, the hippocampus lies in the medial temporal lobes, forging its strongest connections with the surrounding cortical tissue that has been, accordingly, designated the parahippocampal cortex, as well as two other structures termed the entorhinal and perirhinal cortices. ${ }^{6}$ These, however, are only three of a number of other neural structures found in the subcortical (anterior thalamic nuclei, mammillary bodies, septal nuclei, and amygdala) and cortical layers (cingulate gyrus, retrosplenial, insular, inferior temporal, and frontal lobe cortices) with which it is well connected. It receives, in fact, convergent input from nearly all association cortex centers of the brain. Moreover, within the hippocampus, they are widely distributed with recurrent interconnections between all major principal neurons. A unique feature of the hippocampus is its capacity for rapid synaptic plasticity, driven by the long-term potentiation effect, the first physiologically relevant plastic mechanism discovered, ${ }^{9}$ a feature well suited to the formation of memory traces. These attributes very likely confer on the hippocampus a vital capacity for participation in many higher order functions.

How, and whether, what appears to be a uniquely human neural architecture may contribute to even higher order cognitive function is, as yet, unknown. While physical representations originating from sensory input may be more easily assimilated into theoretical models, semantic issues and abstract conceptions, for example, clearly lie beyond substantiation in current speculation.

\section{Introduction to neuroethics: history of its development as a discipline and basis of its necessity}

While the label "neuroethics" is quite new and can be traced back to the beginning of the 21 st century, ${ }^{10}$ issues arising from the interaction between neuroscience and ethics have been an object of interest by ethicists, particularly philosophers, even before the birth of neuroethics as a formally identified discipline. ${ }^{11}$ From ancient Greece onward philosophers have focused on human mental activities as the element peculiar to human identity. Two avenues have been traditionally developed within the general conception of mind: a nonmaterialistic and idealistic approach (ie, the mind is made of a special stuff not reducible to the brain); and a materialistic approach (ie, the mind is no more than the product or the property of the brain).
Both interpretations assume a dualistic theoretical framework: the human being is constituted from two completely different dimensions, which have completely different properties with no interrelations between them, or, at most, a relationship mediated solely by an external element. The most famous expression of this dualistic framework is the philosophy of the Frenchman René Descartes, who spoke of the mind as res cogitans and the body as res extensa in order to stress their differing natures; the contact between them is made possible through an external element, namely the pineal gland.

Despite a reductive interpretation of the mind-brain relationship proclaimed by some contemporary philosophers, ${ }^{12}$ such a dualistic approach to human identity is increasingly criticized by contemporary neuroscience and by the neuroethical and neurophilosophical understanding emerging from it. ${ }^{13}$ Contemporary neuroscience increasingly shows that the special feature of the human brain is its plasticity and its relationality: the human being starts from a particular natural, ie, genetic and neuronal endowment, that can then be deeply shaped through his own epigenetic, ie, cultural influence. ${ }^{14}$ Starting from this scientific premise, neuroethics and neurophilosophy can be developed as nonreductionist cultural endeavors. In this perspective our neuronal identities can be summarized through the expressions "being-in-the-worldwith-others" and "being-in-the-process-of-becoming". ${ }^{15,16}$ Relationality is an essential feature of the brain. This quality is as such not explainable in reductionistic terms; the neural processes that organize the external processes in relational terms cannot be exactly located in the brain because they are the result of the mutual interaction of different cerebral areas. The question regards not a specific neural content but rather a specific neural form, or better, a specific neural organization. ${ }^{17}$

Thus, at the beginning of the 21 st century, neuroethical and neurophilosophical reflections are stressing a theoretical approach to the brain's formal elements and organization, ie, to its plasticity, relationality, and complexity, as a possible common ground for a dialogue between different perspectives. A philosophy of the brain is what is needed so that neuroethics may better develop a conceptual reconciliation of dissonant visions. ${ }^{18}$

\section{Neuroethics as metascientific assessment of neuroscience}

The division between fundamental neuroethics and practical or applied neuroethics is well known. ${ }^{10}$ The former concerns the impact of neuroscience on our ethical practice and concepts, eg, identity, consciousness, and free will. For this reason, it 
has been defined as a "neuroscience of ethics". The latter focuses on the ethical implications of contemporary neuroscientific applications, eg, neuroimaging, lie-detection, and mind reading. For this reason, it has been defined as an "ethics of neuroscience". An ethics of neuroscience seems to be the most popular meaning of neuroethics, at least among the general public. Yet, a proper ethics of neuroscience can be developed only by beginning from a theoretical assessment of the impact of neuroscientific language and categories on ethics, ie, from an adequate fundamental epistemological grasp of neuroethics.

Besides the two aforementioned meanings of neuroethics, a third possible development is that of theoretical neuroethics which, according to Georg Northoff, focuses on the impact of an ethical concept on its neuroscientific study on the one hand, and on the impact of the empirical findings on the ethical concept in question. ${ }^{19}$

Theoretical neuroethics focuses on the mutual relationship between neuroscience and ethics, thereby promoting an interdisciplinary approach. Generally speaking, what is increasingly stressed is the extra-scientific premises and impact of neuroscientific language. As recently outlined in Critical Neuroscience, ${ }^{20}$ the epistemological studies of the 20th century have shown that science cannot be explained solely by a positivist objectivity. Scientific knowledge is in some ways the result of social mediation and construction. Thus, in order to improve the dialogue between different perspectives, a potentially fruitful declination of neuroethics is as an epistemological assessment of neuroscience, ie, a critical reflection about its premises, results, possibilities, and uncertainties. ${ }^{21}$ From a neuroethics that is adopted as a metascientific assessment of neuroscience there emerges an evolutionary and developmental perspective, which locates the human brain and mind within a biosocial framework; in this perspective, a dialogue between different values may be encouraged. A nonreductionist approach to the human being seems in line both with recent developments of neuroscience and with the need of keeping the human, ie, of respecting the human dignity assumed as a metacultural and metaethical property of the human as such. A complex and plastic identity gives us an ethical tool for respecting human dignity.

\section{Preserving the human element in neuromodulation of free will: reflections on a metaneuroethics for decision making}

Perhaps no feature so characteristically identifies the human being as the ability to choose. Human freedom, understood as the "innate right of each person to a sphere of agency in which to pursue his ends" is universally recognized and valued. ${ }^{22}$ Philosophers have debated its characteristics for millennia, and the common man fought for its possession. Today, decision making is being explored in a new way, with tools and methods unavailable to prior eras, those of science and the empirical process in which it participates. Such exploration promises a new understanding of the biological factors that underpin the act of decision making. The understanding that is offered, though, is descriptive and factual, and so lacks normative content. What, then, is to be made of the gap between fact and value? And how can a truly human notion of freedom's value be preserved? Neuroethics is the discipline that attempts to reconcile these two domains. The ensuing discussion considers these questions in light of a neuroethics grounded in contemporary neuroscientific findings and conjoined to a classical human anthropology of means and goals.

\section{The modern predicament}

Almost everyone is nowadays aware of modern neuroscience discoveries that were unknown and inaccessible only a decade ago, including insight into the cerebral circuitry of self-regulation. Key centers subserving emotional regulation, ${ }^{23,24}$ execution of motor tasks, ${ }^{25}$ decision making, ${ }^{26}$ and valence centers, ${ }^{27}$ for example, have been identified and the extended circuits through which they mediate their influence, either implicated, or in the process of characterization. Based on numerous studies, it has been shown that the dorsolateral prefrontal cortex (DLPFC) constitutes a major executive center exerting direct and indirect control over subordinate neural structures. ${ }^{28,29}$ Increased DLPFC activation, for example, is correlated with suppression of hippocampal activity and impaired sensory retention, ${ }^{30}$ and also with regulation of neural activity in the amygdala related to strong emotional expression. ${ }^{31}$ Other structures include, though are not limited to, the subcortical basal ganglia, thalamus, and anterior cingulate and parietal cortices. ${ }^{32}$ Preliminary work, moreover, is beginning to reveal coordinated and dynamic cerebral activity patterns that appear to be associated with the complex act of volition. ${ }^{33}$ From these and other studies the emerging picture is one of increasing clarity with regard to the hierarchical and integrative circuitry participating in the latter stages of the execution of willful acts. Importantly, these studies also reveal the human being to be an integral agent with the capacity to self-initiate interactions with a complex cultural and environmental milieu.

The cognitive events that may precede willful execution are themselves the focus of numerous studies ${ }^{34,35}$ that for 
the most part have been constrained by the methodological limitations and conceptual uncertainty of a nascent field. Preliminary schemes have attempted to dissect the evaluative processes into constituent modules or as a stochastic progression in what is obviously a complex and manifold process, with yet to be determined results. Much attention has been directed to neural mechanisms that may encode value, though these have been typically couched in a conceptual language of reward salience and not rationally designated.

The physical processes that may underpin the goals, intentions, deliberations, and choices that constitute the will, and that uniquely identify the human being, remain largely unknown. Complicating the assignment of empirically identified physical processes to such phenomenological referents is the use of epistemological frameworks drawn from distinct fields and for which the conceptual sets are not wholly reconcilable. Neuroscience employs, for example, empirical and theoretical notions characteristic of the physical sciences to which corresponding phenomenological theories are strictly irreducible. The resulting attempts at a conceptual reconciliation remain, therefore, semantically obscure. Phenomenologically, the self is the primary source of our actions, includes one's personal identity, is self-conscious of its intentions, and operations, and expresses agency. Acting, in turn, is inclined toward goals, oriented by one's "love" for their goods, and guided by rational deliberation. The decision-making process is thus manifold, physically indeterminate, and ontologically extended. Nevertheless, its physical platform is undeniable in its necessity, if not in its sufficiency. ${ }^{36}$

Moreover, a conflicting issue has been the neural freedom of the act of choosing. The free exercise of will means that nothing is fully determinative of one's actions except one's choices.

This understanding has been challenged on two fronts: by a philosophy of science that is metaphysically grounded on the material composition of the brain and that stresses causal closure, ${ }^{37}$ and by empirical assessments purporting to show correlative neural events that precede the phenomenological observations of intent. ${ }^{38}$ On such a grounding, notions of freely made decisions have been rebuffed in favor of retroactively posited epiphenomena, which bear no relation to the causal foundation on which a given action is executed. ${ }^{39}$ The near universal phenomenological experience of self-agency with its obvious physical consequences, a large body of increasingly sophisticated system theory underwriting causally efficacious and downwardly operative effects, ${ }^{40}$ and integrationist and complexity accounts of self and agency, however, have conspired to render such illusory accounts as prematurely stated. Succinctly stated, our current neuroscientific knowledge, in reference to the fundamental structure and operational functions of the human brain, is insufficient for anyone to draw a conclusion regarding the issue of free will, but this has not been a deterrent to its manipulation.

The necessity of a material, neural platform that is somehow participatory in executing intentions makes available the possibility of physical intervention that can circumvent the free exercise of personal agency.

Indeed, the improved knowledge of some regulatory circuits has permitted, and prompted, the development of proposals for their modulation. These trace their origin to therapeutic need, a context within which proposals for modulating free will initially received justification. ${ }^{41}$ Neuromodulation has been recommended, for example, for patients suffering various psychiatric disorders of will, including those with obsessive-compulsive disorder, ${ }^{42}$ major depressive disorder, ${ }^{43}$ and Parkinson's disease. Medical therapy is not the only rationale that has been offered to justify external control over behavior, however. Circumstances in which there is a compelling need to protect society from external threat of those who will not, or perhaps cannot, regulate potentially psychopathic or criminal behavior have also prompted proposals for neuromodulation of free will. ${ }^{44,45}$ Furthermore, proposals to achieve limited mind control have arisen in applications of national defense, ${ }^{46}$ nor are these alone. In each of the latter cases there is a presupposition of addressing a significant personal or social need; yet, there is a clear progression away from a justification based on medical disability, with its intent of restoring lost function to one in which normal function is itself modified. Indeed, in light of such perceived "needs", it is significant to recall the general trend of neuromodulation in practice, whereby therapeutic procedures soon metamorphose into efforts at neuroenhancement, in which the intended modification is to exceed the normal cognitive capacities of healthy individuals. In our brief discussion here, we will argue that a renewed concept of freedom that emphasizes its goal-oriented function will better ground ethical considerations of proposals for the neuromodulation of free will than alternative proposals that neglect the intersection of agent and destination; an ethos and a teleos rather, by which self-agency is determinative of self-transformation.

The notion that it may be possible to modify, or partially mitigate, free will by some form of neural intervention has many implications for the circumstances, manner, or purposes for which it may be considered. The near universal, one may 
say instinctive, recognition of freedom ${ }^{22}$ raises the question of what it is that is being valued, how it is interpreted in our contemporary understanding, and what is its hermeneutic potential for identifying a terrain that may be appropriated for neuromodulation. What is being valued is, in fact, readily apparent from the obvious intensity with which freedom is pursued. The common, and hence commonly accepted, notion of free will is the capacity to exercise a choice in the selection of an option of one's preference, unhindered by external restraint.

What is distinctive in a contemporary understanding is the locus to which the common emphasis situates, within the act of choosing. In a pre-Kantian era the emphasis was directed toward the goal that was being sought. The focal shift introduced by $\mathrm{Kant}^{47}$ and Descartes, ${ }^{48}$ however, that emphasized the decision-making act itself, subordinated the natural world to its willful manipulation. This emphasis, that then continued through the positivist cycle of Comte, ${ }^{49}$ and that reached its apogee with Sarte, ${ }^{50}$ has thus collapsed the notion of any sacrosanct terrain into which the will may be barred, including the human person. In the now positivistic temperament, neuroscience offers a fresh and fertile field in which to maneuver. However, modifying the neural apparatus needed for the exercise of free will poses a quandary. Doing so mitigates its operation. Yet, this also devalues the function of "willing" and so makes moot the justification on which its modification is predicated. So, on what grounds can modification be pursued? Proceeding, in fact, tacitly acknowledges that in the absence of value the sole recourse is to a personally proclaimed legitimation. ${ }^{38}$ So, we may ask, should we extinguish the will solely on a basis of self-created value?

\section{Beyond acting}

The contradiction made evident in our modern predicament is revealing in its inability to reconcile the universally proclaimed value of free will with the limited perspective currently given to its function. In a modern context the exclusive focus on the act of choosing disregards what the act is intended to do, ie, to link the agent with his intended goal. Within a classical and broader view, that incorporates the goal for which the choice is made, the agent is united with the object of his intentions. Significantly, such unification enables the agent to acquire qualities which are afforded by the object, and for which it was originally sought. ${ }^{51,52}$ Indeed, in classical Aristotelian and Thomistic terms, performance is necessarily oriented toward goals in order to secure their goods. When such goods are acquired, a disposition is created for their reacquisition. Simply put, we think of what we are attracted to thinking of, and we are attracted to what we think of, a reflection amplified in each passage.

Neuroscientifically, this process mediates a reorganization of the neural substratum. ${ }^{53}$ Such a neural shaping, in fact, is likely to entail plastic events that are well characterized in the literature of learning and habit formation. ${ }^{54,55}$ Moreover, when the intentional mechanism is itself "connected" to values, such as the desire for justice, the attendant neural changes, which constitute physically verifiable events, themselves incorporate these notions in the process of integration into the brain's physical platform. ${ }^{36}$ Unification thus reveals a latent capacity for renewal and recreation in each individual, and so a power for personal transformation, that is made available in the free exercise of choice. ${ }^{56}$ The value of freedom, which in a modern view rests solely in the act of choosing, is thus revealed as derivative and contingent upon a capacity for transformation that lays latent within the individual, and in which the neural apparatus is fundamentally needed.

The neuroscience of this transformation is thus pertinent to an ethic of neuromodulation of decision making. In a naturalistic sense it is instantiated in the modified neural apparatus. Its normative qualification ${ }^{57}$ rests on the proprietary claim of the agent, entitling the individual alone to dominion over his self-determinative capacity and the fruits acquired in the ensuing self-transformation, a qualification, in fact, that is already universally recognized in the United Nations Declaration of Human Rights. The normative qualification also establishes, moreover, a phenomenological sphere within which intervention can be circumvented. While its corresponding and requisite neural platform is only beginning to be identified, some zones are evident and more likely to be revealed with time. Intended actions, for example, clearly emerge from a deliberative and intentional background and are effectuated through terminal psychosomatic circuits. Against this backdrop, the DLPFC, certain valence circuits which have been evolutionarily designed for individual and species survival, ${ }^{58}$ and features of the neural platform that have undergone neuroplastic modifications to accommodate the experiential consequences of willed events, may be included.

In particular, the holistic nature of the entire neural platform should be emphasized, within which the phenomenological experience of the self is integrated. This confers upon the brain in its totality a unique normative status of teleological dominion. ${ }^{36}$ Significantly, emphasizing the will's instrumental capacity to neurally transform the agent forestalls the legitimacy of breaching its operation. Unlike the modern predicament, in which the "will in action" is distinguished 
as its only valued feature, and where its exercise can be so extended to effect even its dismissal, the "will to transform" thus circumvents external intervention.

How are we, then, to understand the will to transform as an ethic grounding efforts to modulate free will? In light of the universally recognized value of freedom, it becomes clear that one is speaking of a defining feature of the human person. Given such foundational discourse, it cannot be sufficient to elaborate conceptual paradigms based on a flexible consensus alone. What is required is a conception of free will grounded on a human anthropology of self-transformation, one that moves beyond partial phenomenological attributes toward a comprehensive view embracing the full range of its operative dynamic. Such a conception recognizes the individual's right to a determination and possession of his own cognitive destiny, free from unqualified intervention.

\section{Keeping the human in personal responsibility and decision making: ethical reflections on the concept of self and neural enhancement via neuropharmacology and neurotechnology}

Since antiquity, man has sought procedures or substances that either increase courage and strength in battle or duration and endurance in work and sports or increase memory and keenness in intellectual pursuits. Yet, only the modern era has successfully developed effective pharmaceuticals and enhancement techniques capable of improving behavioral, cognitive, and working performance in healthy subjects. Beginning in the 1950s, substances that actively modulate brain neurotransmitter function, ie, neuropsychopharmaceuticals, were employed therapeutically to alter the natural progression of psychiatric and neurological diseases. Today, however, the intent is no longer exclusively therapeutic, and such substances are increasingly used principally to improve quality of life. In the past decade, for example, the indiscriminate usage of serotonergic reuptake inhibitors, the so-called "happiness pills", taken to face daily scholastic, working, and even existential trials, generated vigorous public debate. ${ }^{59}$ Yet, even more significant than mood alteration is the emerging frontier of cerebral and mind enhancement, which intentionally seeks to exceed the normal and preexisting abilities of the individual rather than limit itself to the care of pathological conditions. This frontier will require even closer scrutiny.

\section{Pharmacology in the quest for cognitive enhancement}

Recent discoveries in neuroscience, in fact, that have enabled an improved understanding of the physiological and neurochemical basis of cognitive function, have also permitted the development of products that can improve intellectual performance in healthy individuals in the domains of reasoning, memory, attention, executive function, and language. Some of these substances methylphenidate, marketed under the trade designation Ritalin, and modafinil, sold as Provigil - that are now commonly designated as enhancers, but which also have an extensive history of therapeutic use, have already been employed to improve cognitive function. ${ }^{60}$ Others, including pharmaceuticals which have been used to preserve memory in patients suffering Alzheimer's disease, like memantine, are now in the midst of clinical trials for their efficacy in healthy subjects. ${ }^{61}$

The use of these drugs for "neuronal doping" has stimulated considerable commercial interest in the pharmaceutical industry and has propelled an increasing exploration of a number of so-called high performance requests. ${ }^{62}$

Such trends are a cause for concern. Neuroenhancement induces physiochemical modification of the neuronal processes and a plastic neurobiological manipulation of the nervous connections, all for the declared intention of increasing memory, attention, and $\operatorname{mood}^{63}$ beyond normal physiological boundaries.

We may ask whether this ongoing use reflects only a cultural, almost juvenile, need to be perpetually superefficient or whether it represents a new permissible frontier in the development of neurotechnologies. ${ }^{64} \mathrm{And}$, if the latter, how should it be incorporated into operational protocols and guidelines so as to conform to the deontological norms customarily used in medical and surgical procedures. ${ }^{65}$ In fact, it is not possible to escape the moral ramification of neuroenhancement, with its consequent neuronal modeling and alteration of the very perception of oneself.

\section{Cerebral electrostimulation methodologies in neuroenhancement efforts}

With the progressive use of neurotechnology, the noninvasive techniques of noncerebral electroneurostimulation, ${ }^{66}$ such as transcranial magnetic stimulation, electroencephalography, and functional magnetic resonance imaging neurofeedback, ${ }^{67-69}$ or partially invasive procedures, such as cortical brain stimulation and deep brain stimulation, are increasingly likely to be used in normal subjects to improve psychomotor and cognitive performance, and not simply in patients diagnosed with psychiatric pathologies. ${ }^{70}$ Research on healthy 
subjects, in fact, has revealed an improvement in linguistic abilities, learning, and memory as well as increased stamina and improved physical prowess similar to that observed in the use of "doping substances". ${ }^{71}$ There has also been reported fatigue resistance and improvement in physical performance, ${ }^{72}$ similar to that observed with doping substances.

A corollary problem, that has originated within the context of cognitive ergonomics, concerns whether noninvasive neurostimulation, which has been shown experimentally to improve cognitive performance in healthy subjects, can permissibly be used to improve individual performance in specific environments, as for example at school or at work. ${ }^{73}$

The effects of neurostimulation on attention and memory are comparable to those generated by amphetamines and raise similar ethical concerns. Of considerably greater import, however, and no less remarkable, is the demonstrable ability to effect changes in the capacities for decision making and in the execution of moral judgments. ${ }^{74-81}$ While current protocols indicate that neuroenhancement effects are only transient and observed only in the laboratory, it remains theoretically possible for prolonged daily stimulation to increase the duration and intensity of such effects with resultant long-term behavioral effects. Theoretically, therefore, neurostimulation methods can lead to their abuse and to a dependence on them. ${ }^{82}$ Thus, even though the individual may remain productive in terms of work performance and satisfy ergonomic criteria, he would in reality have created a condition of cognitive dependence that may also impact decision making, and that is socially and ethically unacceptable.

Some authors, moreover, based on the serendipitous finding that hypothalamic deep cerebral stimulation improves associative memory and that stimulation of the ventral striatum, a nucleus of the encephalic basal ganglia, selectively induces positive emotions, ${ }^{83,84}$ have proposed recurrent cerebral stimulation of these structures to improve memory or mood in normal subjects. ${ }^{85}$ Apart from the problems associated with cost-benefit concerns regarding neurointervention, even if minimally invasive, the much more troublesome concern resides in the complex entanglement of medical, ethical, and social issues associated with the use of procedures of enhancement in healthy subjects for the sole purpose of improving his or her personal or community objectives, a "cognitive neurosurgery" to improve the mind in a manner analogous to aesthetic surgery to embellish the body.

Such issues, unfortunately, are no longer only theoretical, but in their current, dramatically real context need to be reflected on to avoid dangerous "neurocosmetic" drifts. For it is likely that by remodeling cerebral circuits, neuromodulation will also influence the neurobiological networks involved in the perception of self, in the formulation of judgments and beliefs, and in the execution of decisions. ${ }^{86}$ Novel technologies will inevitably emerge both in neuropsychopharmacology and neurosurgery, permitting even more precise molecular specificity. While this may bring new and positive therapeutic options, it will also introduce new neuroethical dilemmas. ${ }^{87,88}$ In particular, any neurotechnological intervention, whether cognitive pharmacological, surgical, or prosthetic, that aims to modify or strengthen individual performance, will have to adhere to a logic to remain within borders that do not fundamentally alter what is uniquely human, and that constitutes the essence of every individual.

Clearly, such fundamental elements of the human person as the sense of self, personhood, moral judgment, and agency constitute ontological and phenomenological spheres whose boundaries must remain inviolable. Moreover, different and novel perceptions of the image of oneself, resulting from neurotechnological developments and their applications, should not be dismissive but rather completely respectful of what remains deeply human also in a new vision of man.

\section{Conclusion}

As neuroscience accumulates ever more factual information on brain operation, the normative problems raised by these findings become increasingly acute. In the past decade, as neuroscience has moved from peripheral sensory and motoric investigations to more central brain operation, ethical trends have shifted from an ethics concerned with the practice of neuroscience to interpretive aspects of human anthropology. No longer solely concerned with pharmacological enhancement, increasingly it reflects on the substance of our self-interpretation. This review has emphasized the progressively shifting landscape of neuroethics that is propelled by the quest to understand our neural nature and by the success of the neuroscientific enterprise. The authors' concern is that in our rush to change, we not overlook the prize already in our possession, the human mind in its manifold expression and oriented naturally to meaning and transcendence through beauty, truth, and ethics. Keeping the human is more than a recommendation, it is a recognition that what is kept will be the patrimony that we bequeath to our future.

\section{Disclosure}

The authors report no conflicts of interest in this work.

\section{References}

1. Van Essen DC, Ugurbil K. The future of the human connectome. Neuroimage. 2012;62(2):1299-1310. 
2. BrainFacts.org [Homepage on Internet]. Available from: http://www. brainfacts.org/press/new-web-site-brainfactsorg-launches. Accessed December 5, 2015.

3. Society for Neuroscience (webpage on the Internet). About Neuroscience. Available from: http://www.sfn.org/about/about-neuroscience. Accessed December 20, 2014.

4. Eichenbaum H. Hippocampus: cognitive processes and neural representations that underlie declarative memory. Neuron. 2004;44(1): 109-120.

5. Buckner RL, Krienen FM. The evolution of distributed association networks in the human brain. Trends Cogn Sci. 2013;17(12): 648-665.

6. Bird CM, Burgess N. The hippocampus and memory: insights from spatial processing. Nat Rev Neurosci. 2008;9(3):182-194.

7. Broadbent NJ, Scquire LR, Clark RE. Spatial memory, recognition memory, and the hippocampus. Proc Natl Acad Sci USA. 2004;101(40): 14515-14520.

8. Howard MW, Eichenbaum H. The hippocampus, time, and memory across scales. J Exp Psychol Gen. 2013;142(4):1211-1230.

9. Lømo T. The discovery of long-term potentiation. Philos Trans $R$ Soc Lond B Biol Sci. 2003;358(1432):617-620.

10. Roskies A. Neuroethics for the new millenium. Neuron. 2002; 35(1):21.

11. Evers K. Towards a philosophy for neuroethics. An informed materialist view of the brain might help to develop theoretical frameworks for applied neuroethics. EMBO Rep. 2007;8 Spec No:S48-S51.

12. Churchland P. Neurophilosophy: Toward a Unified Science of the MindBrain. Cambridge, MA: MIT Press; 1986.

13. Evers K. Neuroéthique. Quand la matière s'éveille [When the matter arises]. Paris: Éditions Odile Jacob; 2009.

14. Changeux JP. The Physiology of Truth. Cambridge, MA: Harvard University Press; 2009.

15. Gillett GR. Subjectivity and Being Somebody: Human Identity and Neuroethics. Exeter: Imprint Academic; 2009.

16. Gillett GR. The subjective brain, identity, and neuroethics. Am J Bioeth 2009;9(9):5-13.

17. Northoff G. What are the subjective processes in our brain? Empirical and ethical implications of a relational concept of the brain. Am J Bioeth 2009;9(9):27-28.

18. Northoff G. Minding the Brain: A Guide to Philosophy and Neuroscience Houndmills, Basingstoke, Hampshire: Palgrave Macmillan; 2014

19. Northoff G. What is neuroethics? Empirical and theoretical neuroethics. Curr Opin Psychiatry. 2009;22(6):565-569.

20. Choudhury S, Slaby J, editors. Critical Neuroscience: A Handbook of the Social and Cultural Contexts of Neuroscience. Chichester: Wiley \& Sons Ltd; 2012.

21. Farisco M. In need of meta-scientific experts? AJOB Neuroscience 2014;7(2):243-245.

22. Valentini L. Human rights, freedom, and political authority. Political Theory. 2012;40(5):573-601.

23. Ochsner KN, Ray RR, Hughes B, et al. Bottom-up and top-down processes in emotion generation: common and distinct neural mechanisms. Psychol Sci. 2009;20(11):1322-1331.

24. Goldin PR, McRae K, Ramel W, Gross JJ. The neural bases of emotion regulation: reappraisal and suppression of negative emotion. Biol Psychiatry. 2008;63(6):577-586.

25. Schroeder S, Verrel J. Cognitive processing and motor execution in the lexical decision task: a developmental study. Psychon Bull Rev. 2014;21(2):496-504

26. Orr LE, Russ BE, Cohen YE. Disruption of decision making capacities in the rhesus macaque by prefrontal cortex TMS. Abstract presented at Thirty Eighth Annual Meeting S Neuroscience. 2008;875.24(RR86); Washington, DC.

27. Vuilleumier P, Sander D. Trust and valence processing in the amygdala. Soc Cogn Affect Neurosci. 2008;3(4):299-302.

28. Funahashi S. Neuronal mechanisms of executive control by the prefrontal cortex. Neurosci Res. 2001;39(2):147-165.
29. Wager TD, Davidson ML, Hughes BL, Lindquist MA, Ochsner KN. Prefrontal-subcortical pathways mediating successful emotion regulation. Neuron. 2008;59(6):1037-1050.

30. Anderson MC, Ochsner KN, Kuhl B, et al. Neural systems underlying the suppression of unwanted memories. Science. 2004;303(5655): 232-235.

31. Phelps EA. Emotion and cognition: insights from studies of the human amygdala. Аnпu Rev Psychol. 2006;57:27-53.

32. Glannon W. Neuropsychological aspects of enhancing the will. The Monist. 2012;95(3):378-398.

33. Mulder MJ, Wagenmakers EJ, Ratcliff R, Boekel W, Forstmann BU. Bias in the brain: a diffusion model analysis of prior probability and potential payoff. $J$ Neurosci. 2012;32(7):2335-2343.

34. Fellows LK. The cognitive neuroscience of human decision making: a review and conceptual framework. Behav Cogn Neurosci Rev. 2004; 3(3):159-172.

35. Gold JI, Shadlen MN. The neural basis of decision making. Ann Rev Neurosci. 2007;30:535-574.

36. Sanguineti JJ. Can free decisions be both intentional and neural operations? In: Sanguineti JJ, Acerbi A, Lombo JA, editors. Moral Behavior and Free Will: A Neurobiological and Philosophical Approach. Rome: IF Press; 2011:179-202.

37. Kim J. The myth of nonreductive materialism. Proceedings and Addresses of the American Philosophical Association. 1989;63(3):31-47.

38. Libet B. The neural time factor in conscious and unconscious events. In: Ciba Foundation Symposium \#174 Experimental and Theoretical Studies of Consciousness. Chichester: Wiley Press; 1993:123-146.

39. Pierre JM. The neuroscience of free will: implications for psychiatry. Psychol Med. 2014;44(12):2465-2474.

40. Murphy N. Avoiding neurobiological reductionism: the role of downward causation in complex systems. In: Sanguineti JJ, Acerbi A, Lombo JA, editors. Moral Behavior and Free Will: A Neurobiological and Philosophical Approach. Rome: IF Press; 2011:201-222.

41. Glannon W. Neuromodulation, agency and autonomy. Brain Topogr. 2014;27(1):46-54.

42. Mallet L, Polosan M, Jaafari N, et al; STOC Study Group. Subthalamic nucleus stimulation in severe obsessive-compulsive disorder. $N$ Engl $J$ Med. 2008;359(20):2121-2134.

43. Schlaepfer TE, Cohen MX, Frick C, et al. Deep brain stimulation to reward circuitry alleviates anhedonia in refractory major depression. Neuropsychopharmacology. 2008;33(2):368-377.

44. Focquaert F. Mandatory neurotechnological treatment: ethical issues. Theor Med Bioeth. 2014;35(1):59-72.

45. Canavero S. Criminal minds: neuromodulation of the psychopathic brain. Front Hum Neurosci. 2014;8:124.

46. Gordijn B, Buyx AM. Neural engineering: the ethical challenges ahead. In: Giordano JJ, Gordijn B, editors. Scientific and Philosophical Perspectives in Neuroethics. Cambridge: Cambridge University Press; 2010:283-301.

47. Rohlf M. Immanuel Kant [webpage on the Internet]. The Stanford Encyclopedia of Philosophy. Stanford, CA: Stanford University; 2010. Available from: http://plato.stanford.edu/entries/kant/. Accessed May 20, 2010.

48. René Descartes. Discourse on Method. Adam C, Tannery P, editors. Indianapolis: Hackett; 1993.

49. Bourdeau M. Auguste Comte [webpage on the Internet]. The Stanford Encyclopedia of Philosophy. Stanford, CA: Stanford University; 2008 [updated September 30, 2013]. Available from: http://plato.stanford. edu/entries/comte/. Accessed October 16, 2014.

50. Flynn T. Jean-Paul Sartre [webpage on the Internet]. The Stanford Encyclopedia of Philosophy. Stanford, CA: Stanford University; 2004 [updated December 5, 2011]. Available from: http://plato.stanford.edu/ entries/sartre/. Accessed October 16, 2014.

51. Wojtyla K. The Acting Person. Dordrecht, Holland: D Reidel Publishing; 1979.

52. Rhonheimer M. Norm-ethics, moral responsibility, and the virtues. In: Murphy WF, editor. The Perspective of the Acting Person. Washington, DC: Catholic University Press; 2008:18-36. 
53. Hampson P. By knowledge and by love: the integrative role of habitus in Christian psychology. Edification. 2012;6(1):5-18.

54. Daw ND, Shohamy D. The cognitive neuroscience of motivation and learning. Social Cognition. 2008;26(5):593-620.

55. Rankin $\mathrm{CH}, \mathrm{Abrams} \mathrm{T}$, Barry RJ, et al. Habituation revisited: an updated and revised description of the behavioral characteristics of habituation. Neurobiol Learn Mem. 2009;92(2):135-138.

56. Merzenich M. Soft-Wired, How the New Science of Brain Plasticity Can Change Your Life. San Francisco, CA: Parnassus Publishing; 2013.

57. Northoff G. Neuroscience of decision making and informed consent: an investigation in neuroethics. J Med Ethics. 2006;32(2):70-73.

58. Haber SN, Knutson B. The reward circuit: linking primate anatomy and human imaging. Neuropsychopharmacology. 2010;35(1):4-26.

59. Kramer PD. Listening to Prozac. A psychiatrist explores antidepressant drugs and the remaking of the self. Viking, New York 1993.

60. Amodio VA. Neuroscienze: farmaci "potenzianti" per modificare il normale funzionamento del corpo e della psiche [Neuroscience: enhancing drugs to modify the normal functioning of body and mind]. Il Nuovo Medico d'Italia. 2014. Available from: http://www.numedionline.it/apps/ essay.php?id=14624. Accessed January 16, 2014.

61. Repantis, D. Acetylcholinesterase inhibitors and memantine for neuroenhancement in healthy individuals: A systematic review. Pharmacological Research. 2010;61(6).

62. Farah MJ, Illes J, Cook-Deegan R, et al. Neurocognitive enhancement: what can we do and what should we do? Nat Rev Neurosci. 2004;5(5): 421-425.

63. Parens E. How far will the treatment/enhancement distinction get us as we grapple with new ways to shape ourselves? In: Marcus SJ, editor. Neuroethics: Mapping the Field. New York, NY: The Dana Press; 2002: $152-158$.

64. Benanti P. Neuroenhancement in young people: cultural need or medical technology? AJOB Neuroscience. 2000;1(1):27-29.

65. Gini A, Rossi J, Giordano J. Considering enhancement and treatment: on the need to regard contingency and develop dialectic evaluation. AJOB Neuroscience. 2010;1(1):25-27.

66. Sironi VA. Origin and evolution of deep brain stimulation. Front Integr Neurosci. 2011;5:42.

67. Zotev V, Krueger F, Phillips R, et al. Self-regulation of amygdala activation using real-time FMRI neurofeedback. PLoS One. 2011; 6(9):e24522.

68. Zotev V, Phillips R, Yuan H, Misaki M, Bodurka J. Self-regulation of human brain activity using simultaneous real-time fMRI and EEG neurofeedback. Neuroimage. 2014;85(Pt 3):985-995.

69. Clark VP, Parasuraman R. Neuroenhancement: enhancing brain and mind in health and in disease. Neuroimage. 2014;85 Pt 3:889-894.

70. Sironi VA, Porta M. Il controllo della mente. Scienza ed etica della neuromodulazione cerebrale [The Mind Control. Science and Ethics of Brain Neuromodulation]. Roma-Bari: Laterza; 2011. Italian.

71. Utz KS, Dimova V, Oppenländer K, Kerkhoff G. Electrified minds: transcranial direct current stimulation (tDCS) and galvanic vestibular stimulation (GVS) as methods of non-invasive brain stimulation in neuropsychology - a review of current data and future implications. Neuropsychologia. 2010;48(10):2789-2810.

72. Cogiamanian F, Marceglia S, Ardolino G, Barbieri S, Priori A. Improved isometric force endurance after transcranial direct current stimulation over the human motor cortical areas. Eur J Neurosci. 2007;26(1): 242-249.

Neuroscience and Neuroeconomics

\section{Publish your work in this journal}

Neuroscience and Neuroeconomics is an international, peer-reviewed, open access journal focusing on the identification of brain structures and measurement of neural activity related to behavior, behavioral predictions, and decision making in health and disease. The manuscript
73. Normann C, Berger M. Neuroenhancement: status quo and perspectives. Eur Arch Psychiatry Clin Neurosci. 2008;258(Suppl 5):110-114.

74. Normann C, Boldt J, Maio G, Berger M. [Options, limits and ethics of pharmacological neuroenhancement]. Nervenarzt. 2010;81(1):66-74. German.

75. Fecteau S, Knoch D, Fregni F, Sultani N, Boggio P, Pascual-Leone A. Diminishing risk-taking behavior by modulating activity in the prefrontal cortex: a direct current stimulation study. J Neurosci. 2007;27(46): 12500-12505.

76. Fecteau S, Pascual-Leone A, Zald DH, et al. Activation of prefrontal cortex by transcranial direct current stimulation reduces appetite for risk during ambiguous decision making. $J$ Neurosci. 2007;27(23): 6212-6218.

77. Fumagalli M, Giannicola G, Rosa M, et al. Conflict-dependent dynamic of subthalamic nucleus oscillations during moral decisions. Soc Neurosci. 2011;6(3):243-256.

78. Karim AA, Schneider M, Lotze M, et al. The truth about lying: inhibition of the anterior prefrontal cortex improves deceptive behavior. Cereb Cortex. 2010;20(1):205-213.

79. Knoch D, Gianotti LR, Pascual-Leone A, et al. Disruption of right prefrontal cortex by low-frequency repetitive transcranial magnetic stimulation induces risk-taking behavior. $J$ Neurosci. 2006;26(24): 6469-6472.

80. Mameli F, Mrakic-Sposta S, Vergari M, et al. Dorsolateral prefrontal cortex specifically processes general - but not personal - knowledge deception: Multiple brain networks for lying. Behav Brain Res. 2010; 211(2):164-168.

81. Priori A, Mameli F, Cogiamanian F, et al. Lie-specific involvement of dorsolateral prefrontal cortex in deception. Cereb Cortex. 2008;18(2): 451-455.

82. Young L, Bechara A, Tranel D, Damasio H, Hauser M, Damasio A. Damage to ventromedial prefrontal cortex impairs judgment of harmful intent. Neuron. 2010;65(6):845-851.

83. Ferrucci R, Fumagalli M, Mameli FA, Priori A. Etica della neurostimolazione [Ethics of neurostimulation], in Sironi A.Vittorio, Porta M, Il controllo della mente. Scienza ed etica della neuromodulazione cerebrale. Roma-Bari: Laterza; 2011:223-240.

84. Okun MS, Bowers D, Springer U, et al. What's in a "smile?" Intraoperative observations of contralateral smiles induced by deep brain stimulation. Neurocase. 2004;10(4):271-279.

85. Okun MS, Mann G, Foote KD, et al. Deep brain stimulation in the internal capsule and nucleus accumbens region: responses observed during active and sham programming. J Neurol Neurosurg Psychiatry. 2007;78(3):310-314.

86. Synofzik M, Schlaepfer TE. Stimulating personality: ethical criteria for deep brain stimulation in psychiatric patients and for enhancement purposes. Biotechnol J. 2008;3(12):1511-1520.

87. Sironi VA, Gini A. Neuroethical implications of neuromodulation using deep brain stimulation. Poster presented at: International Neuroethics Society Annual Meeting; November 8, 2013; San Diego, CA.

88. Sironi VA, Gini A. Poster presented at the Neuronanotechnology and neuroethics. International Neuroethics Society Annual Meeting; November 8, 2013; San Diego, CA, USA. management system is completely online and includes a very quick and fair peer-review system. Visit http://www.dovepress.com/testimonials. php to read real quotes from published authors. 